This PDF is a selection from a published volume from the National Bureau of Economic Research

Volume Title: The Intended and Unintended Effects of U.S. Agricultural and Biotechnology Policies

Volume Author/Editor: Joshua S. Graff Zivin and Jeffrey M. Perloff, editors

Volume Publisher: University of Chicago Press

Volume ISBN: 0-226-98803-1; 978-0-226-98803-0 (cloth)

Volume URL: http://www.nber.org/books/perl10-1

Conference Date: March 4-5, 2010

Publication Date: February 2012

Chapter Title: An Overview of the Intended and Unintended Effects of U.S. Agricultural and Biotechnology Policies

Chapter Authors: Joshua S. Graff Zivin, Jeffrey M. Perloff

Chapter URL: http://www.nber.org/chapters/c12104

Chapter pages in book: (p. 1 - 12) 


\title{
An Overview of the Intended and Unintended Effects of U.S. Agricultural and Biotechnology Policies
}

\author{
Joshua S. Graff Zivin and Jeffrey M. Perloff
}

The eight chapters in this volume were presented at the National Bureau of Economic Research Agricultural Economics Conference, March 4-5, 2010. The conference focused on two central issues confronting agricultural economists and policymakers today. Five of the chapters examine the efficiency and distributional effects of crop subsidy programs. The other three chapters examine the effects of biofuels and other biotechnology policies and innovations on commodity prices and social welfare. All the chapters bring new empirical methods and new data to analyze issues that are at the forefront of debates in agricultural policy circles. The importance of institutional details and unintended consequences are common themes that run throughout.

\section{Agricultural Policy}

Most introductory economics textbooks blithely describe agricultural markets as unregulated and perfectly competitive. Nonetheless, virtually every aspect of agricultural markets is regulated or subject to other government interventions. The U.S. government regulates farm production, prices, land use, environmental quality, organic foods, and food safety, among many other aspects of agriculture. The government also provides food or food stamps to poor consumers and trade assistance and insurance to farmers. Despite peri-

Joshua S. Graff Zivin is associate professor of economics at the University of California, San Diego, where he holds faculty positions in the School of International Relations and Pacific Studies and the Department of Economics. He is research director for international environmental and health studies at the Institute on Global Conflict and Cooperation and a research associate of the National Bureau of Economic Research. Jeffrey M. Perloff is professor in the Department of Agricultural and Resource Economics at the University of California, Berkeley, and a former member of the National Bureau of Economic Research's Board of Directors. 
odic debates in Congress about deregulating these markets and some reduction in direct transfers to agricultural producers, the types of government intervention in food and agriculture has, if anything, increased over the years.

Shortly after the end of World War I, the U.S. government started aggressively intervening in agricultural markets. A complex set of regulations evolved that provided support for growers of major field crops (barley, corn, upland cotton, oats, rice, sorghum, and wheat). From 1973 to 1995, farmers almost always received deficiency payments: the difference between the market price and a target price times a quantity determined by a farmer's "base" acreage and crop yield.

Although it is not well known to most economists, agricultural price supports in the past several decades have been part of what are now known as "crop insurance" programs. Farmers used a specified quantity of their crop as collateral for a nonrecourse loan equal to that quantity times a price called the commodity loan rate. The loan rate serves as a support price. In most versions of the program, after the crop was harvested, farmers repaid the loans if the market price exceeded the support price; otherwise, they essentially sold the crop to the government by forfeiting the actual physical product.

In recent years, Congress passed an omnibus "Farm Bill" package of legislation that modifies the federal programs roughly every five years. The most recent federal agricultural legislation, the 2008 Farm Bill, allocates $\$ 288$ billion to farmers (e.g., income support and insurance), to consumers (e.g., food stamps), and for biofuel research and production from 2008 through 2012. Of this total, $\$ 43.3$ billion goes to the commodity loan program.

The traditional agricultural price support subsidies - as typically described in intermediate microeconomics textbooks - are no longer used. The 1996 Federal Agriculture Improvement and Reform (FAIR) Act, also known as the Freedom to Farm Act and as the Agricultural Market Transition Act, made major changes in agricultural policy. In theory, it was supposed to wean farmers from government support. A farmer's eligibility for support was no longer based on historical production; farmers could plant whatever crops they desired (including soybeans, which were not traditionally supported), and farmers received loan deficiency payments based on the difference between the market price and a target support price (the loan rate). These payments were relatively infrequent in some years for some crops.

To aid in the transition from agricultural price supports, FAIR provided a seven-year period of income support through direct payments that were (allegedly) independent of production and were known in advance. This "temporary" direct income support is now well entrenched — indeed, it was expanded in two subsequent farm bills - and costs $\$ 5$ billion per year. The federal government also provides countercyclical payments that are triggered by low prices but not tied to current production; loan deficiency payments and marketing loans, which use loan rates to support market prices; 
and a subsidized crop insurance program. According to proponents, this significantly modified and expanded insurance program would help farmers manage financial risk and reduce the likelihood that Congress would have to pass supplemental ad hoc disaster assistance. Insurance is provided for more than 350 commodities in all states and Puerto Rico, and more than 80 percent of eligible acres are now insured under the program.

All five of the chapters on agricultural policy focus on aspects of price supports or federal crop insurance. Two chapters examine who captures agricultural support, taking account of vertical relations. Barry K. Goodwin, Ashok K. Mishra, and François Ortalo-Magné estimate the distribution of agricultural subsidies in upstream land markets, while Rachael E. Goodhue and Carlo Russo investigate whether downstream processors capture a large share of the subsidies. These chapters examine many of the most important current policy questions.

The other three of these chapters focus on the newly important crop insurance program. Bruce A. Babcock examines the politics and the efficiency of the U.S. Crop Insurance Program. Ethan Ligon looks at the supply effects of the new specialty crop insurance program. Jeffrey LaFrance, Rulon Pope, and Jesse Tack examine how crop farmers respond to changes in risk more generally.

\section{The Distribution of Agricultural Policy Rents and Market Power in Vertical Markets}

The record clearly shows that, throughout the history of the commodity support program, Congress intended that the beneficiaries be family farmers, the salt of the earth. However, it is well known that most of the support funds go to relatively large farms owned by corporations. Although some of these are family farm corporations, many others are owned by Fortune 500 companies, members of Congress, and by other wealthy people with no obvious connection to farming. What is not as well known is that a large share of these transfers goes to owners of firms in other related markets.

Traditionally, most analyses of the effects of agricultural programs have focused - not surprisingly — on the directly regulated agricultural crop market. However, as these markets are intimately connected to other markets, it is important to examine the spillover effects. Two of the chapters in this volume examine how agricultural transfers are shared with other vertically related markets. One chapter looks downstream at processors, while the other looks upstream at landlords.

The two chapters individually and collectively make a significant contribution to our understanding of agricultural support programs by showing that much of the support payments go to people other than Congress's intended recipients, farmers. In addition, the chapters indicate new efficiency harms from the commodity support program that have not been previously identified. 
Barry K. Goodwin, Ashok K. Mishra, and François Ortalo-Magné (GMOM) focus on how the commodity support program benefits are distributed. Because these subsidies have been provided for over three-quarters of a century and are expected to persist, GMOM argue that farm land values should capture the subsidy benefits. They estimate the extent of this capitalization and conclude that landowners are the major beneficiaries of the farm programs. New owners of land pay prices that reflect expected future benefits, so the ultimate recipients of the benefits are the land owners at the time the benefits are instituted. Moreover, as nearly half (45 percent) of U.S. farmland is owned by nonfarmers, and 57 percent of agricultural landlords are nonfarm corporations or individuals who work in or are retired from nonfarm-related activities, much of the benefits go to nonfarmers. Goodwin, Mishra, and Ortalo-Magné carefully examine the role of leasing and show that lease rates capture much of the agricultural subsidy payments.

Although a number of previous studies examined the capitalization of price subsidies into farm values, GMOM are the first to resolve a number of very vexing data problems. More important, they have data on lease arrangements and rates, so they can estimate how landlords and farmers split the government transfers. Also, for the first time in this literature, they determine how the market values the insurance feature of farm programs. They show that programs that provide insurance and lower the risk from uncertain farm earnings cause the share lease rate premium to fall substantially.

They examine a variety of farm support programs, which ranged from price-support payments based on current market conditions to other programs that were, in principle, not connected to market conditions or production. They find that the effects on land values were smallest for programs that were decoupled from output and were supposed to be transitory, moderate for programs whose payments may have signaled future benefits, and largest for price support programs.

In "Modeling Processor Market Power and the Incidence of Agricultural Policy: A Nonparametric Approach," Rachael E. Goodhue and Carlo Russo investigate the link between downstream, processor market power and U.S. agricultural policies. They examine marketing loan and pre-1986 deficiency payment programs in which payments are made to farmers only if the market price was less than a target price.

This chapter makes an important contribution to the literature by examining how federal programs affect firms' ability to exercise market power and how some of the rents intended for farmers are captured by downstream firms. Although earlier studies indicate that firms in many relevant markets have substantial oligopoly or oligopsony power, traditionally most analyses of federal subsidy programs have assumed that these markets are competitive. Given the assumption of competition, most previous studies of the effects of agricultural price support policies have examined the size of the transfer to farmers relative to the deadweight loss. However, if, for example, 
downstream processors possess oligopsony market power, they can extract some of the policy rents.

Goodhue and Russo examine the wheat market, which is highly competitive (with over 160,000 farms) and the vertically related milling market (with a four-firm concentration ratio of 57 percent), which they argue is not perfectly competitive. They focus on how the policy affects the margin between the price of flour and the price of wheat, taking account of the possibility that the policy may change millers' behavior. The premise of the chapter is that if, all else is the same, the oligopsony margin increases when farmers receive deficiency payments, then by comparing periods with and without payments, millers' oligopsony power can be detected. Their approach uses the policy as an experiment, exploiting the changes in millers' strategic pricing behavior as an identification device for oligopsony power.

They use an innovative nonparametric model. Hopefully, by using a nonparametric model, they are less vulnerable to specification bias than in the traditional structural approaches to estimating market power. Unlike the now standard structural or reduced-form approaches to estimating market power, they compare the outcomes of using constrained and unconstrained sliced inverse regressions to identify which factors affect millers' pricing behavior.

Constraining the factors in the sliced inverse regression to generate coefficients that are easily interpreted using economic theory does not affect the results. Their results are consistent with the story that a change in policy regime triggers a change in pricing behavior. For years when the policy is binding, millers appear to absorb as least as large of a share of a marginal cost increase as they do in years when the policy is not binding.

They conclude that wheat millers were able to extract an additional $23 \phi$ or $24 \phi$ per hundred weight of flour by increasing their marketing margins in years farmers received program payments. This increase was approximately 10 percent of the estimated marketing margin in years farmers received program payments. However, the amount of the increase depends on market conditions: the difference in the expected margin between the two policy regimes is smaller when farmer supply is low, suggesting that millers' extraction of policy rents has a nonlinear relationship with the market price.

The chapter concludes that U.S. wheat millers are able to extract some of the transfer payments intended for farmers. Thus, the analysis suggests that the general assumption that competitive models may be a good approximation for imperfectly competitive agricultural markets does not necessarily hold, particularly if distribution, as well as efficiency, is a concern.

\section{Insurance}

Bruce Babcock's chapter analyzes whether the crop insurance program provides farmers with an efficient risk transfer mechanism that the private 
sector cannot provide. Historically, private crop insurance markets have failed. A key question is whether this failure was due to the systemic nature of crop losses, which prevents pooling, or a lack of demand. As Babcock notes, if the private sector cannot provide adequate crop insurance, then a government risk transfer market could improve welfare. However, if the private insurance markets do not exist because of a lack of demand, then the government's crop insurance program could result in large welfare losses. Thus, he focuses on whether there is unmet demand for crop insurance.

Proponents' justification for heavily subsidizing insurance rates in recent years was that virtually no farmers were buying insurance. Babcock examines how farmers' demand for insurance responds to a change in the actuarial fairness of the insurance. His task is difficult because the government's rate making methods are not consistent with actuarial fairness. A significant contribution of his chapter is the construction of a data set that allows him to estimate the degree of actuarial fairness of corn, soybean, and wheat contracts.

In years in which insurance premiums exceed indemnities, crop insurance companies get to keep a portion of the difference, which is called the net underwriting gain. For example, in 2004, premiums exceeded claims by \$979 million, and underwriters kept $\$ 848$ million, including $\$ 692$ in underwriting gains. From 1998 through 2009, underwriters had gains in all but one year.

The government provides reinsurance to underwriters. Babcock concludes that program costs would be substantially lower if the federal government took all the risk from the crop insurance program rather than buying an overpriced insurance policy from the crop insurance companies.

Farmers' demand for crop insurance depends on expected returns and risk reduction. Farmers pay only about 41 percent of the amount needed to cover insured losses. This large subsidy means that most farmers will get substantially more back from the program than they pay it, but there is wide variance in actuarial fairness over crops and over time. Babcock develops a method to isolate the demand for risk reduction from the demand for expected returns. He can estimate the demand for actuarially fair insurance contracts because before the recent increase in the size of the subsidies, rates were less than actuarially fair, whereas after the change, they were more than actuarially fair.

The vast majority of corn, soybean, and wheat farmers obtained less than the 85 percent maximum available coverage in 2009. Babcock finds that farmers who are offered more actuarially fair insurance would increase their insurance coverage. The reason that very few farmers bought insurance in the past was because the rates were much less than actuarially fair. $\mathrm{He}$ finds that more than half of the acreage that was able to be insured at higher coverage levels at actuarially fair incremental premiums was insured. That is, a large number of producers find that the risk reductions offered by revenue insurance generate significant value. Thus, he concludes that it is not 
necessary to heavily subsidize the rates to make them more than actuarially fair for many farmers to buy insurance.

Of course, a plausible explanation for the large premium subsidies is effective lobbying by interest groups. Consequently, he examines the interest groups who capture rents from the program to illuminate the political forces that have led to an expansion of these subsidies. This explanation is consistent with Becker's theory of legislation as a reflection of economic payoffs from the application of pressure by affected interest groups. The effectiveness of interest group lobbying is illustrated by the congressional ban on price competition between crop insurance agents striving for farmers' business. Babcock concludes that the chief beneficiaries of this lobbying activity are agents and farmers in the Great Plains.

The justification offered for providing such insurance is to help reduce risk of producers and thereby induce them to produce more to benefit consumers. We know from Babcock's careful study of the actuarial fairness of this insurance that the government is subsidizing the insurance so that taxpayers' outlays exceed the gains to producers. Thus, if insurance is to raise overall welfare, there needs to be a substantial benefit to consumers. Ethan Ligon asks whether insurance against low yields on fruits and vegetables has a substantial effect on quantities and prices and, hence, whether producers and consumers benefit from the provision of government insurance.

Insurance policies for wheat date back to 1938, and policies for other program crops were introduced many years ago. However, coverage for specialty crops - particularly fruits and vegetables - is a relatively recent event. In 1981, 28 crop-county insurance contracts were offered for fruits and vegetables in California. That number rose to 500 in 1989, and large increases followed in 1990 and 1995 so that now about 2,300 crop-county contracts are available.

Farmers face greater risk for specialty crops, particularly fruits and vegetables, than for cereal crops because specialty crops have greater price variation than do storable commodities. However, although that greater risk might increase the demand for insurance relative to storable commodities, most fruits and vegetables in California are marketed using vertical intermediaries, partially to help manage risk, which lowers demand for insurance all else the same. In addition, specialty crops are grown in small geographical areas so that a single weather or other shock tends to have a larger effect on aggregate supply than for crops grown over larger areas. Bad weather could reduce supply and dramatically increase price, given inelastic demand curves, so that the amount of harm (if any) to an individual producer is unclear. Consequently, specialty farmers' demand for yield insurance might be low. These factors may explain why only a quarter of eligible California acreage was insured in 1988. More recently, expansion of crops covered, provision of quasi-mandatory insurance, and subsidies have increased usage of insurance. 
Ligon is able to identify the effects of insurance because coverage for particular fruits and vegetables in particular counties was introduced slowly over time. Expansion of coverage results from a government agency's bureaucratic decision, which Ligon shows is unlikely to be based on maximizing farmers' profits.

Thus, Ligon exploits variation in the timing of the introduction of crop insurance policies across crops and counties to estimate the effects of crop insurance on output and price, using instruments to control for the timing of the introduction of insurance. He finds that the introduction of insurance for a given crop statistically significantly increases production by 164 percent for tree crops but does not have a statistically significant effect on nontree crops. This difference across crops may be a consequence of the much larger investment at risk in perennial crops than in annual crops. Moreover, although he clearly shows that insurance leads to greater production of tree crops, he notes that some of this expansion may reflect substitution away from other crops so that total production may not rise in proportion.

Ligon then estimates a corresponding average demand curve and finds that it is extremely flat. Thus, from Ligon's careful study, we can conclude that expansion of coverage of insurance to more specialty crops has very small effects on consumer welfare even given substantial output effects.

Jeffrey LaFrance, Rulon Pope, and Jesse Tack develop a new approach to analyzing the impact of the government's insurance programs and other policies on farmers' risk response using aggregate data. Farmers have to choose how many inputs to use before output prices are revealed. When analyzing supply responses, economists have to model the process by which farmers form expectations, which is a particularly difficult challenge with aggregate data. LaFrance, Pope, and Tack, in a tour de force, develop a comprehensive structural econometric model of variable input use; crop mix and acreage choices; investment and asset management decisions; and consumption, savings, and wealth accumulation in a stochastic dynamic programming model of farm-level decision making over time. LaFrance, Pope, and Tack develop necessary and sufficient condition on cost and technology to allow variable input demand equations to be specified as functions of input prices, quasi-fixed inputs, and total variable cost. They develop and estimate a flexible, exactly aggregable, and economically regular model of ex ante variable input demands.

They develop a new class of variable input demand systems in a multiproduct production setting. All of the models in this class can be estimated with observable data, are exactly aggregable, are consistent with economic theory for any von Neumann-Morgenstern expected utility function, and can be used to nest and test exact aggregation, economic regularity, functional form, and flexibility. Implications of monotonicity, concavity in prices, and convexity in outputs and quasi-fixed inputs are developed for a specific subset of this class of models.

LaFrance, Pope, and Tack use a coherent framework to estimate this 
model while dealing with the major questions that arise in estimating production functions: choice of functional form; degree of flexibility; conditions required for and regions of economic regularity; consistency with aggregation from micro- to macro-level data; and how best to handle simultaneous equations bias, errors in variables, and latent variables in a structural econometric model.

They use their new model to analyze acreage and supply decisions under risk for ten crops that represent roughly 95 percent of total farm revenue from crop production and nearly all crop acreage: soybeans, corn, cotton, hay, potatoes, rice, sugar beets, sugarcane, tobacco, and wheat. They estimate Euler equations for the excess return to investing in agriculture, personal consumption expenditures, and the rate of return to stocks as measured by the Standard \& Poor's (S\&P) 500 index. Because they are careful to include government payments in crop revenues, their estimated model can be used to examine how behavior changes in response to those payments. They take account of risk aversion in agricultural production and investment decisions.

Using the LaFrance, Pope, and Tack model, one can analyze the effects of any policy that alters the distribution of agricultural crop income on the choices that restore equilibrium. A major implication is that agricultural policy may affect other markets by changing nonagricultural investment and consumption. The estimated social value of public crop insurance is likely to be reduced as more margins for adjustment (arbitrage conditions) are included in the analysis. Unlike in traditional, static studies (that essentially estimate long-run effects), this model can be used to distinguish short-run and long-run effects. In particular, public subsidies that raise the return to insurance have larger long-run than short-run effects.

\section{Biofuels and Biotechnology}

While the processing of foodstuffs into fuel has been around for at least a century, interests in large-scale biofuel production in the United States dates back to the oil crises of the 1970s, which ultimately led to the creation of the National Renewable Energy Laboratory. Continued concerns about energy security as well as increasing awareness about climate change led to the promulgation of the Energy Policy Act of 1994, whose goal was to promote the production and use of renewable fuels. Nearly a decade later, the Energy Policy Act of 2005 was enacted, which created the first national renewable fuel standard (RFS). This RFS called for annual biofuel usage of 7.5 billion U.S. gallons by 2012 and established blending requirements for refiners and importers of gasoline.

Within the first year of the enactment of the Energy Policy Act of 2005, the United States surpassed Brazil as the largest producer of ethanol in the world, with nearly five billion gallons of mostly corn-based ethanol production in 2006. By the end of the following year, annual federal support for 
the ethanol industry had topped $\$ 3.25$ billion. ${ }^{1}$ In 2008 , the production of U.S. corn ethanol had nearly doubled, consuming one-third of U.S. corn production and raising the price of corn. ${ }^{2}$ Concerns about the effects of these requirements on agricultural commodity prices led to a revision of the National Renewable Fuel Standard in 2009. The new requirements establish volumetric standards for cellulosic and advanced biofuels that would use nonedible feedstocks in the production process.

Although a growth industry has sprung up of academics studying these issues, most of these studies take place in isolation, typically focusing on one particular aspect of the problem rather than the linkages between them. The remaining three chapters in this volume examine the complex relationship between biotechnology policy and agriculture. Two chapters look at the link between policies that encourage biofuel production and food prices. Some commentators have speculated that biofuel demand contributed significantly to the worldwide food price crisis in 2008. A third chapter investigates whether genetic engineering can help keep food prices low in the face of the increased demand due, in part, to higher levels of biofuels production.

The immediate future of the U.S. ethanol market will be shaped by two policies. The U.S. RFS described in the preceding and the U.S. Environmental Protection Agency's ethanol "blend wall," which dictates the maximum amount of ethanol that can be mixed with petroleum in gasoline used by conventional automobiles. The blend wall was set at 10 percent. It has subsequently (October 2010) been raised to 15 percent, but only for recent model automobiles. Future increases are likely as long as the blend wall prevents ethanol from reaching the RFS level. Hertel and Beckman develop a theoretical framework to analyze the linkages between energy and agricultural markets under these policies. When neither policy is binding, consumers are able to respond to all realizations of oil prices by changing their biofuel mix. Thus, the transmission of energy price volatility to commodity price volatility is high and corn price volatility is low in response to traditional supply-side shocks. When either policy binds, the biofuel portion of demand for corn becomes more inelastic (on average). In this case, the agricultural commodity price impacts from energy price volatility are smaller, but the impacts from corn supply volatility are magnified.

The authors use an applied general equilibrium analysis to assess the magnitude of these effects. They begin by validating their empirical model against historical data and then use it to project the impacts in 2015 when the RFS takes effect. They find that when no policies bind, energy price volatility accounts for 0.53 of the total variation in corn prices. When the RFS is just binding, the share of energy price volatility is cut in half; when

1. "Federal Financial Interventions and Subsidies in Energy Markets in 2007," Energy Information Administration, http://www.eia.doe.gov/oiaf/servicerpt/subsidy2/pdf/execsum.pdf.

2. See http://www.nass.usda.gov/. 
the blend wall is binding, it accounts for an even smaller share of total corn price variation. Where both policies are on the verge of binding - as will be the case if the blend wall is raised until it reaches fifteen billion gallons in total - the relationship between energy and corn price volatility is almost entirely eliminated. In contrast, the impact of corn supply shocks on prices is 57 percent larger than under the nonbinding case, boosting world price volatility by 25 percent. These numbers are large and suggest that, at least for biofuel feedstocks, energy policy may become a more important source of agricultural price uncertainty than traditional agricultural policies.

Concerns about energy security and the environment have led to a range of policies to promote the production of biofuels. The impact of this production on food prices and land use has led to additional interventions designed to shift policy incentives toward advanced biofuels made from nonfood-based feedstocks. Xiaoguang Chen, Haixiao Huang, Madhu Khanna, and Hayri Önal (CHKO) develop a dynamic, multimarket equilibrium model that analyzes the markets for fuel, food, and livestock. After validating the model with historical data, CHKO use the estimated model to simulate the impacts of two U.S. policies: the biofuel mandates under the U.S. RFS and these mandates accompanied by targeted subsidies designed to make advanced biofuels more competitive with gasoline for fuel blending.

Simulations under the biofuel mandate alone suggest that 50 percent of the cumulative biofuel production from 2007 to 2022 under the RFS will be met through corn ethanol production. As a result, corn prices will be significantly higher and gasoline prices will be lower than they would be without the mandate. On net, this policy will result in a $\$ 122$ billion increase in the present value of social welfare compared to a no-biofuel policy scenario. Adding subsidies to the mandate reduces the share of corn ethanol to 10 percent of biofuel totals, leading to lower food prices (due to assumed technological improvements in corn production and reduced demand for corn for ethanol) as well as lower fuel prices. Despite these gains by consumers, the policy results in a net welfare loss of roughly $\$ 79$ billion as the cost to tax payers and agricultural producers are quite substantial. Thus, in order for the current configuration of biofuels policy to improve social welfare, the incremental environmental and energy security benefits resulting from these policies must exceed roughly \$200 billion over the 2007 to 2022 period.

Increased global demand for biofuels is placing increased pressure on agricultural systems at a time when traditional sources of yield improvements have been mostly exhausted, generating concerns about the future of food prices. Steven Sexton and David Zilberman estimate the impact of global adoption of genetically engineered (GE) seeds on food supply. The conceptual model illustrates two key points. First, because GE crops are typically designed to minimize crop damages, they will be most valuable in locations facing high pest pressure. Second, because GE crops increase damage abatement, they increase the value of the marginal product of other 
production inputs and thus help to increase yield beyond the typical "gene effect" estimated in previous literature.

Sexton and Zilberman's estimation model exploits spatial and temporal variation in the adoption of GE crops to identify the average yield effect due to GE technologies among adopters - the average treatment effect on the treated. The yield gains range from 65 percent for GE cotton to 12.4 percent for soybeans. Separating the analysis by developed and developing countries, yield increases appear to be three- to fivefold higher in the developing world, consistent with the notion that they are experiencing higher pest pressure. They also find modest evidence in support of learning-bydoing as farmers gain experience with these new technologies. Applying these figures to the 2008 food crisis suggests that corn, soybean, wheat, and rapeseed prices would have been between 27 and 43 percent higher absent GE crop plantings. Stated another way, achieving the 2008 harvest without GE technologies would have required an additional twenty million hectares of land planted using traditional seeds. Genetically engineered crops appear to play an important role in arbitrating tensions between energy production, environmental protection, and global food supplies.

This book has two main themes. First, to accurately analyze agricultural and biotechnology policies, one must pay attention to complex institutional rules: the devil is in the details. Second, these policies have many unintended consequences - fostering inefficiency and the redistribution of income intended for producers - in large part because of complex linkages within and across markets.

Chapters 1 (Goodwin, Mishra, and Ortalo-Magné), 2 (Goodhue and Russo), 3 (Babcock), and 4 (Ligon) find that much of the rent from agricultural subsidies designed to help agricultural producers is extracted by processors, landowners, and insurers or lost due to inefficiency. Chapter 5 (LaFrance, Pope, and Tack) argues that current risk policies affect income and wealth over time, thereby affecting future production choices so that the long-run responses to subsidized crop insurance are likely to be larger than the short-run effects. The three chapters on biotechnology emphasize the increasing connections between agricultural and energy markets. Chapter 6 (Hertel and Beckman) shows that ethanol policy is a significant driver of agricultural commodity price levels and volatility. Chapter 7 (Chen, Huang, Khanna, and Önal) emphasizes that policies to manage future food price impacts by moving to cellulosic feedstocks in the production of biofuels will come at high social costs. Chapter 8 (Sexton and Zilberman) finds that the adoption of genetically engineered seeds has played an important role in mitigating recent food price effects - in part due to biofuel subsidiesalthough its role going forward is less clear. Thus, together, these chapters demonstrate that institutional details matter and that even evaluations of fairly narrow policies should be viewed through a broad lens. 